\title{
Interaction between Caregiving Ability and Home Discharge Using Severity Classification upon Discharge
}

\author{
Takashi Kimura ${ }^{1,2}$ \\ ${ }^{1}$ Department of Physical Therapy, ASO Rehabilitation College, Fukuoka, Japan \\ ${ }^{2}$ Department of Rehabilitation Medicine, Saga University Hospital, Saga, Japan \\ Email: t.kimufuku@gmail.com
}

How to cite this paper: Kimura, T. (2022) Interaction between Caregiving Ability and Home Discharge Using Severity Classification upon Discharge. Open Journal of Therapy and Rehabilitation, 10, 9-24. https://doi.org/10.4236/ojtr.2022.101002

Received: November 16, 2021

Accepted: January 4, 2022

Published: January 7, 2022

Copyright () 2022 by author(s) and Scientific Research Publishing Inc. This work is licensed under the Creative Commons Attribution International License (CC BY 4.0).

http://creativecommons.org/licenses/by/4.0/ (c) (i) Open Access

\begin{abstract}
Background: The interaction between self-care and caregiving ability in home discharged stroke patients is unclear. Purpose: This study investigates the interaction between caregiving ability and individual self-care activities for post-stroke patients upon home discharge based on their motor-Functional Independence Measure (m-FIM) score. Methods: A total of 2626 stroke patients registered in the Japanese Rehabilitation Database were retrospectively analyzed. Extracted data were divided into three groups based on the m-FIM score at discharge and classified into two groups based on their discharge destination (home discharge, non-home discharge). After the data were modified as mean-centered values, a hierarchical multiple regression analysis evaluated the change in variance amount $\left(\Delta R^{2}\right)$ using discharge destination as the dependent variable. Model 1 used two independent variables (Rankin Scale and cognitive FIM score), model 2 used two independent variables (caregiving ability and individual self-care), which were added to model 1 , and model 3 used an interaction term value, which was added to model 2 . Furthermore, a simple slope analysis was performed for these interaction effects. Results: The $\Delta R^{2}$ exhibited six and five self-care items in the moderate and mild groups, respectively. The interaction was significant on simple slope analysis in the moderate group for six self-care items (except dressing upper body, toileting, and bowel management) and in the mild group for three self-care items, including dressing upper body, bladder management, and climbing stairs). Conclusion: This study suggests the need for intervention, especially bladder management and single-foot standing ability during step climbing, in stroke patients discharged to home. In addition, caregiving ability is one of the factors that should be considered in mild group.
\end{abstract}




\section{Keywords}

Interaction, Stroke, FIM, Discharge, Caregiving Ability

\section{Introduction}

Stroke is a sudden and unpredictable disease that causes various long-term symptoms and post-stroke disabilities [1]. Stroke patients have various functional disabilities, of which gait and activities of daily living (ADL) disturbances are the most common [2] [3]. Hence, more than half the stroke patients need to be partially or totally assisted by others [4] [5] or family members as caregivers [6] in ADL after discharge. Therefore, caregiving ability and independence level of ADL are essential factors for determining home discharge [6] [7]. On the other hand, caregivers of stroke patients, who provide them nursing care at home, also experience various physical, mental, social, and economic problems that may affect their quality of life [5] [8]. Furthermore, in previous studies, only half of the caregivers were confident about caring for stroke patients, despite their knowledge about stroke-related nursing care [9] [10]. Owing to the high level of proficiency in nursing care skills always required, the stress on the caregivers is higher than that on the stroke patients themselves, and its trends that this stress does not decrease much over the years [11] [12]. This caregiver stress accounts for moving post-stroke patients from home to a nursing facility [13] [14]. Moreover, the dependence level of self-care negatively impacts families' decisions for home discharge, and families prefer high levels of self-care independence in post-stroke patients at home discharge. Despite the extensive literature available on the relationship between ADL and caregiving ability upon home discharge, the interaction between caregiving ability and improvements in individual ADL has not been sufficiently elucidated in stroke patients based on severity classification of paralysis. Interventions related to ADL could differ depending on the existence of an interactive relationship between ADL and caregiving ability. Therefore, to evaluate the interactions between ADL and caregiving ability that could lead to a higher possibility of home discharge, it is important to clarify the existence of an interaction between caregiving ability and ADL.

This study aimed to investigate the interaction between caregiving ability and individual self-care activities for home discharge based on the motor-Functional Independence Measure (m-FIM) score.

\section{Materials and Methods}

\subsection{Subject}

The medical data of 6875 patients with stroke were extracted from the Japan Rehabilitation Database (JRD) in the stroke/recovery rehabilitation phase ward (January 2016 version, https://square.umin.ac.jp/JARD/). We used anonymized 
observational data obtained in normal clinical settings. The need for informed consent was waived due to the retrospective and observational design of the study and the use of secondary data. The original data collection had been approved by the Ethics Committee of the Japanese Association of Rehabilitation Medicine (November 14, 2014). However, the committee did not issue an approval number.

\subsection{Setting}

A flowchart of the subject in this study is shown in Figure 1 [15]. The inclusion criteria were as follows: age, 20 - 100 years; days from onset to admission, 20 200 days; and length of ward stay, 1 - 255 days. Similarly, all data were collected based on FIM at discharge, Rankin scale (RS) at discharge, the destination of leaving the hospital excepting incompletely filed data. The exclusion criteria were death, changing hospital due to sudden turn for the worse and individuals

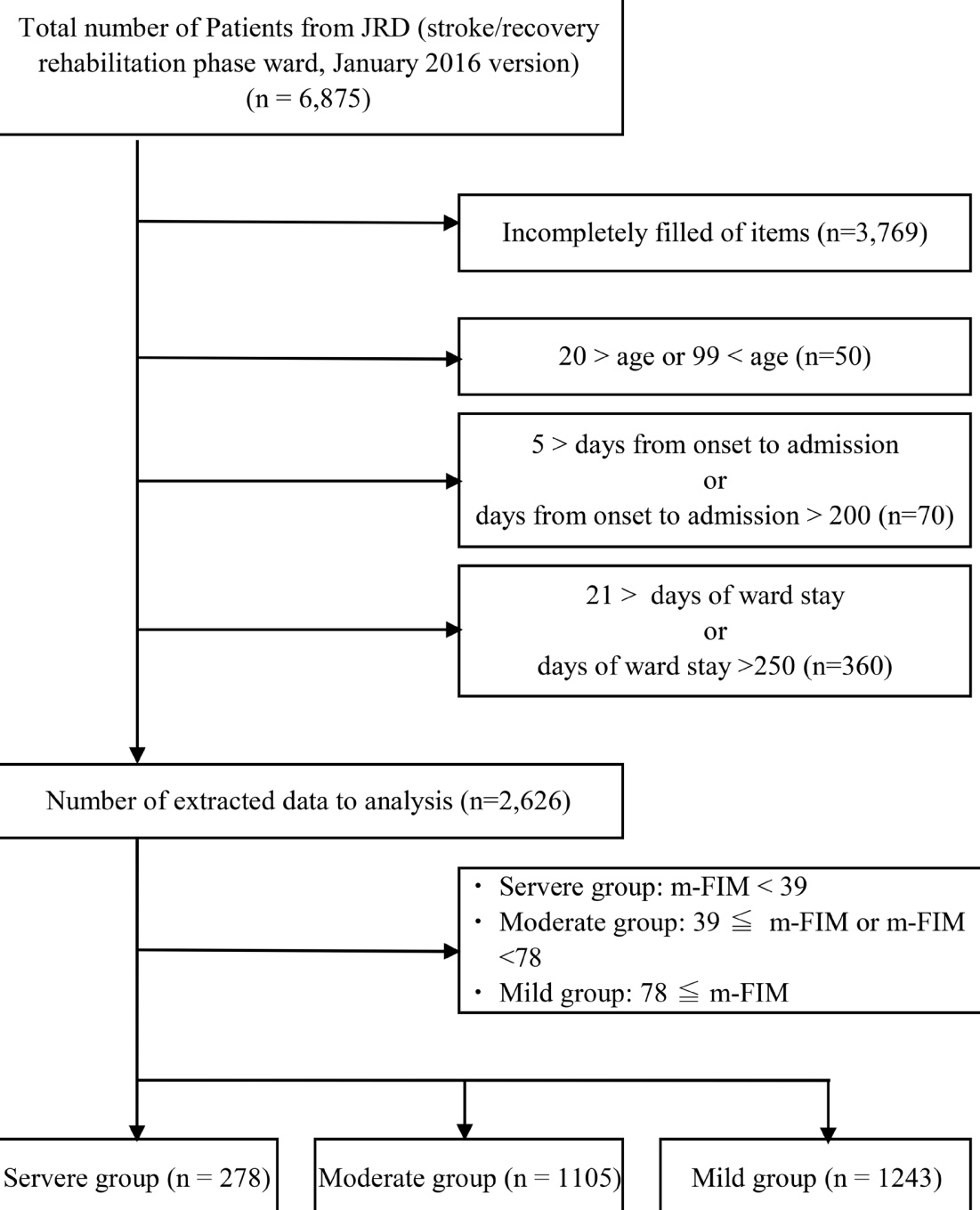

Figure 1. Flowchart of the data sampling with reason for exclusion. JRD, Japanese Rehabilitation Database. Figure partial modified from ref. [15]. 
who lived in nursing homes or other residential facilities prior to stroke onset and finally, the data of 2626 cases were analyzed. Extracted data was divided three groups based on discharged m-FIM score (severe: <39, moderate: more than 39 to fewer than 78, mild: more than 78). The FIM score is reported to have high reliability, validity, and prediction for outcomes concerning the ADL evaluation post-stroke; it consists of $13 \mathrm{~m}$-FIM and 5 cognitive FIM (c-FIM) items, which are evaluated using seven levels [16]. Caregiving ability was defined by the number of people who were available to care for the patient, and was set using a 5 -point ordinal scale: level 1, almost none; level 2, less than one person who is constantly available to provide care; level 3, equivalent to one person who is constantly available to provide care; level 4 , more than one and less than two people who are constantly available to provide care; level 5, equivalent to more than two people who are constantly available to provide care. In this study, the destination after leaving the hospital was categorized as follows: home discharge, non-home discharge like nursing facilities, etc. The stroke type does not generally influence the prognosis [17] [18]. Therefore, this information was excluded from this study. Sex, the duration from the onset to hospital admission, the length of ward stay, the cognitive FIM score, and caregiving ability were set as the general items.

\subsection{Statistical Analysis}

\subsubsection{Hierarchical Multiple Regression Analysis}

First, all data were modified as mean-centered values to avoid multicollinearity among items. The mean-centering value was calculated by subtracting the mean from the raw value. Secondly, the evaluation of each self-care interaction was subsequently performed using hierarchical multiple regression. Hierarchical regression is the way that several regression models are built by adding variables to a previous model at each step. This method allows for the examination of the contribution above and beyond the first group of independent variables. In this study, this analysis used home discharge as the dependent variable in a prediction formula (model 1) using two items as independent variables (RS, c-FIM) to evaluate the influence of the control variables. Model 2 added two items as independent variables (caregiving ability and self-care) to Model 1. In the concept of interaction, the idea of a two-way effect is defined, as opposed to a causal one-way effect. It means that the influence of an independent variable on a dependent variable varied across the levels of a moderating variable. Individual self-care score of m-FIM at discharge was set as the moderating variable in this study [18] [19]. Consequently, a prediction formula, namely "model 3," added an interaction term value to model 2 .

\subsubsection{Simple Slope Analysis}

If an interaction were significant, a simple slope analysis was conducted following the method by Cohen \& Cohen [19] and the Johnson-Neyman technique (JN technique) [20]. The simple slope method evaluates whether the influence of the 
independent variable on the dependent variable is statistically significant when the adjustment variable takes a specific value, and it has been reported that the $\mathrm{JN}$ technique is an effective procedure for investigating the significance of the interaction, when the moderator value is continuous [19] [20]. Rather than testing for significance at fixed values of the moderator, the JN technique solves for the values of the moderator for which the effect of $\mathrm{X}$ on $\mathrm{Y}$ becomes or ceases to be significant. Moreover, it can explain, as a function of the moderator, the lower and upper bounds for the confidence bands estimating the effect of X on Y. A graph of the confidence bands makes it easy to see for which values of the moderator the effect of the focal predictor on the response is significant. The statistical significance level was set at $\mathrm{p}<0.05$. Statistical analyses were conducted using IBM SPSS version 20.0 (IBM Corp., Armonk, NY, USA), and the online software created by Preacher, Curran, \& Bauer was used for simple slope analysis.

\section{Results}

\subsection{General Overview}

Data of 6875 stroke patients are registered on the JRD. Of these, the $4249 \mathrm{pa}-$ tients who failed to meet the inclusion criteria were excluded, and 2626 who met the criteria were ultimately included in this study. Overall, 1096 (41.7\%) participants were female, the home discharge rate was $84.4 \%$, and the median age was 69.3 years. The baseline characteristics of the subjects in each group and the results of comparisons between groups are presented in Table 1. The results showed significance in each group in terms of caregiving ability. In addition, all self-care items showed significance in the moderate group. However, almost of self-care items in the other two groups did not show much significance.

\subsection{Simple Slope Analysis}

Table 2 presents self-care that had significant changes in variance amount in the hierarchical multiple regression, except for the severe group. Figure 2 illustrates the relationship between dependent and independent variables under a moderator of variation (mean $\pm 1 \mathrm{SD}$ ). The simple slope analysis was significant for six self-care items in the moderate group (except dressing upper body, toileting, and bowel management) and three self-care items in the mild group (dressing upper body, bladder management, and climbing stairs). These groups had two self-care items in common: bladder management and climbing stairs. Moreover, caregiving ability interaction had a score of 1 - 2 (three to four people) in the moderate group and $0-1$ (two to three people) in the mild group. Because of the limitation in evaluating continuous variables using the subtest for interaction influence, the region of significance and $95 \%$ confidence interval of the simple slope in each group were calculated. Then, the extracted variable of self-care was significant except grooming and dressing lower body in the mild group (Figure 3). 
Table 1. Descriptive characteristics of the subject at discharge in each group and results of comparison between home discharge and non-home discharge.

\begin{tabular}{|c|c|c|c|}
\hline a) Server group & $\begin{array}{l}\text { Overall } \\
(n=278)\end{array}$ & $\begin{array}{l}\text { Home discharge } \\
\qquad(\mathrm{n}=130)\end{array}$ & $\begin{array}{l}\text { Non-home discharge } \\
\qquad(\mathrm{n}=148)\end{array}$ \\
\hline Age & $76.14 \pm 9.60$ & $74.2 \pm 10.43$ & $77.84 \pm 8.48^{\star \star}$ \\
\hline Female, \%, (n) & $46.4(\mathrm{n}=129)$ & $44.6(\mathrm{n}=58)$ & $45.0(\mathrm{n}=71)$ \\
\hline Days form onset to admission & $40.70 \pm 14.73$ & $41.05 \pm 14.83$ & $40.39 \pm 14.69$ \\
\hline Days of ward stay & $127.28 \pm 40.04$ & $131.35 \pm 42.24$ & $123.7 \pm 37.79$ \\
\hline Caregiving ability & $2.44 \pm 1.02$ & $2.83 \pm 0.93$ & $2.10 \pm 0.97^{\star \star}$ \\
\hline Rankin scale & $4.09 \pm 0.74$ & $3.93 \pm 0.77$ & $4.22 \pm 0.68^{\star *}$ \\
\hline m-FIM & $26.78 \pm 7.56$ & $27.25 \pm 7.72$ & $26.36 \pm 7.43$ \\
\hline c-FIM & $15.88 \pm 6.69$ & $15.98 \pm 6.51$ & $15.79 \pm 6.86$ \\
\hline Eating & $4.07 \pm 1.58$ & $3.99 \pm 1.72$ & $4.14 \pm 1.45$ \\
\hline Grooming & $2.63 \pm 1.40$ & $2.59 \pm 1.42$ & $2.66 \pm 1.39$ \\
\hline Bathing & $1.34 \pm 0.60$ & $1.34 \pm 0.55$ & $1.34 \pm 0.64$ \\
\hline Dressing upper body & $2.00 \pm 1.01$ & $2.09 \pm 1.06$ & $1.92 \pm 0.97$ \\
\hline Dressing lower body & $1.52 \pm 0.80$ & $1.58 \pm 0.89$ & $1.47 \pm 0.70$ \\
\hline Toileting & $1.63 \pm 0.89$ & $1.72 \pm 1.06$ & $1.55 \pm 0.71$ \\
\hline Bladder management & $1.71 \pm 1.02$ & $1.72 \pm 1.04$ & $1.70 \pm 1.01$ \\
\hline Bowel management & $2.24 \pm 1.59$ & $2.30 \pm 1.58$ & $2.18 \pm 1.61$ \\
\hline Gait/Wheelchair & $1.77 \pm 1.20$ & $1.84 \pm 1.21$ & $1.71 \pm 1.19$ \\
\hline Climbing stairs & $1.10 \pm 0.42$ & $1.13 \pm 0.44$ & $1.08 \pm 0.40$ \\
\hline b) Moderate group & $\begin{array}{c}\text { Overall } \\
(n=1105)\end{array}$ & $\begin{array}{l}\text { Home discharge } \\
\qquad(\mathrm{n}=889)\end{array}$ & $\begin{array}{l}\text { Non-home discharge } \\
\qquad(\mathrm{n}=216)\end{array}$ \\
\hline Age & $71.83 \pm 11.77$ & $70.87 \pm 11.98$ & $75.78 \pm 9.96^{\star *}$ \\
\hline Female, \%, (n) & $44.6(\mathrm{n}=493)$ & $44.1(\mathrm{n}=392)$ & $46.8(\mathrm{n}=101)$ \\
\hline Days form onset to admission & $36.47 \pm 14.74$ & $36.43 \pm 14.93$ & $36.62 \pm 13.95$ \\
\hline Days of ward stay & $116.07 \pm 42.97$ & $115.05 \pm 43.26$ & $120.25 \pm 41.59$ \\
\hline Caregiving ability & $2.32 \pm 0.94$ & $2.46 \pm 0.90$ & $1.73 \pm 0.91^{\star *}$ \\
\hline Rankin scale & $3.14 \pm 0.85$ & $3.07 \pm 0.85$ & $3.40 \pm 0.80^{\star *}$ \\
\hline m-FIM & $63.28 \pm 10.79$ & $64.60 \pm 10.37$ & $57.83 \pm 10.83^{\star \star}$ \\
\hline c-FIM & $25.07 \pm 6.42$ & $25.60 \pm 6.35$ & $22.89 \pm 6.28^{\star *}$ \\
\hline Eating & $6.00 \pm 0.97$ & $6.04 \pm 0.96$ & $5.85 \pm 1.01^{\star *}$ \\
\hline Grooming & $5.49 \pm 1.21$ & $5.57 \pm 1.19$ & $5.14 \pm 1.25^{\star *}$ \\
\hline Bathing & $3.78 \pm 1.24$ & $3.88 \pm 1.22$ & $3.37 \pm 1.21^{\star *}$ \\
\hline Dressing upper body & $5.13 \pm 1.49$ & $5.28 \pm 1.44$ & $4.52 \pm 1.55^{\star \star}$ \\
\hline Dressing lower body & $4.86 \pm 1.64$ & $5.04 \pm 1.58$ & $4.15 \pm 1.71^{\star \star}$ \\
\hline
\end{tabular}




\section{Continued}

\begin{tabular}{|c|c|c|c|}
\hline Toileting & $5.29 \pm 1.30$ & $5.40 \pm 1.23$ & $4.81 \pm 1.46^{\star *}$ \\
\hline Bladder management & $5.31 \pm 1.74$ & $5.47 \pm 1.69$ & $4.69 \pm 1.81^{\star \star}$ \\
\hline Bowel management & $5.43 \pm 1.39$ & $5.55 \pm 1.32$ & $4.95 \pm 1.56^{\star *}$ \\
\hline Gait/Wheelchair & $4.65 \pm 1.65$ & $4.69 \pm 1.66$ & $4.50 \pm 1.61^{\star \star}$ \\
\hline Climbing stairs & $2.67 \pm 1.78$ & $2.80 \pm 1.80$ & $2.15 \pm 1.62^{\star \star}$ \\
\hline c) Mild group & $\begin{array}{c}\text { Overall } \\
(n=1243)\end{array}$ & $\begin{array}{l}\text { Home discharge } \\
\qquad(\mathrm{n}=1197)\end{array}$ & $\begin{array}{l}\text { Non-home discharge } \\
\qquad(\mathrm{n}=46)\end{array}$ \\
\hline Age & $65.51 \pm 13.29$ & $65.24 \pm 13.35$ & $72.39 \pm 9.20^{\star *}$ \\
\hline Female, \%, (n) & $38.1(n=474)$ & $37.8(n=452)$ & $47.8(n=22)$ \\
\hline Days form onset to admission & $32.02 \pm 13.94$ & $31.91 \pm 13.97$ & $34.87 \pm 13.14^{\star *}$ \\
\hline Days of ward stay & $83.62 \pm 38.95$ & $83.14 \pm 38.78$ & $95.96 \pm 41.70^{\star *}$ \\
\hline Caregiving ability & $2.19 \pm 0.95$ & $2.22 \pm 0.94$ & $1.37 \pm 0.68^{\star *}$ \\
\hline Rankin scale & $1.79 \pm 0.88$ & $1.78 \pm 0.88$ & $2.02 \pm 1.02^{\star *}$ \\
\hline m-FIM & $85.14 \pm 4.12$ & $85.19 \pm 4.10$ & $83.85 \pm 4.36^{\star *}$ \\
\hline c-FIM & $30.94 \pm 4.76$ & $31.12 \pm 4.64$ & $26.24 \pm 5.25^{\star \star}$ \\
\hline Eating & $6.87 \pm 0.37$ & $6.87 \pm 0.37$ & $6.93 \pm 0.25^{\star \star}$ \\
\hline Grooming & $6.86 \pm 0.41$ & $6.87 \pm 0.40$ & $6.67 \pm 0.67^{\star *}$ \\
\hline Bathing & $6.21 \pm 0.98$ & $6.22 \pm 0.98$ & $5.93 \pm 1.02^{\star \star}$ \\
\hline Dressing upper body & $6.90 \pm 0.36$ & $6.90 \pm 0.35$ & $6.80 \pm 0.54^{\star *}$ \\
\hline Dressing lower body & $6.87 \pm 0.37$ & $6.87 \pm 0.36$ & $6.72 \pm 0.58^{\star \star}$ \\
\hline Toileting & $6.78 \pm 0.43$ & $6.78 \pm 0.43$ & $6.72 \pm 0.46^{\star *}$ \\
\hline Bladder management & $6.88 \pm 0.45$ & $6.88 \pm 0.43$ & $6.74 \pm 0.85^{\star \star}$ \\
\hline Bowel management & $6.71 \pm 0.55$ & $6.72 \pm 0.53$ & $6.57 \pm 0.83^{\star *}$ \\
\hline Gait/Wheelchair & $6.12 \pm 1.49$ & $6.11 \pm 1.51$ & $6.37 \pm 1.02^{\star *}$ \\
\hline Climbing stairs & $5.59 \pm 1.42$ & $5.59 \pm 1.42$ & $5.48 \pm 1.28^{\star \star}$ \\
\hline
\end{tabular}

Item with bold and italic; showing a significant by hierarchical multiple regression analysis. ${ }^{*} \mathrm{p}<0.05,{ }^{* *} \mathrm{p}<0.01$.

Table 2. $\Delta \mathrm{R}^{2}$ value of hierarchical multiple regression analysis for individual self-care in each group.

\begin{tabular}{cccc}
\hline & $\begin{array}{c}\text { Severe group } \\
(\mathrm{n}=278)\end{array}$ & $\begin{array}{c}\text { Moderate group } \\
(\mathrm{n}=1105)\end{array}$ & $\begin{array}{c}\text { Mild group } \\
(\mathrm{n}=1243)\end{array}$ \\
\hline Eating & - & $0.004^{* *}$ & $-^{* *}$ \\
Grooming & - & $0.011^{* *}$ & $0.017^{* *}$ \\
Bathing & - & $0.006^{* *}$ & $-^{* *}$ \\
Dressing upper body & - & $-{ }^{* *}$ & $0.006^{* *}$ \\
Dressing lower body & - & $0.004^{* *}$ & $0.011^{* *}$ \\
Toileting & - & $--^{* *}$ & $-^{* *}$ \\
\hline
\end{tabular}




\section{Continued}

\begin{tabular}{cccc} 
Bladder management & - & $0.007^{* *}$ & $0.007^{\star *}$ \\
Bowel management & - & $-{ }^{* *}$ & $-^{* *}$ \\
Gait/Wheelchair & - & $-{ }^{* *}$ & $-^{* *}$ \\
Climbing stairs & - & $0.005^{* *}$ & $0.003^{\star *}$ \\
\hline
\end{tabular}

Results with bold and italic; showing non-significant by simple slope analysis. $\Delta \mathrm{R}^{2}$ : the change in variance between model 2 and model $3 .{ }^{*} \mathrm{p}<0.05,{ }^{* *} \mathrm{p}<0.01$.

(A) Moderate group

(a) Eating

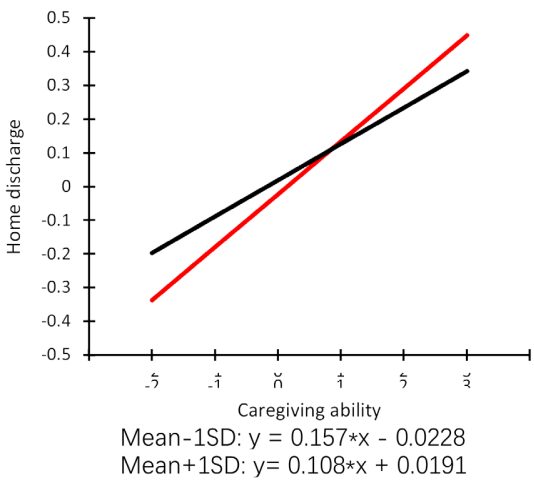

(b) Grooming

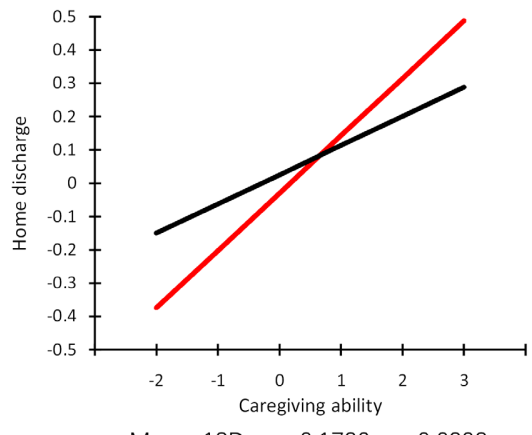

Mean-1SD: $y=0.1726 * x-0.0293$

Mean+1SD: $y=0.0876 * x+0.0261$ (c) Bathing

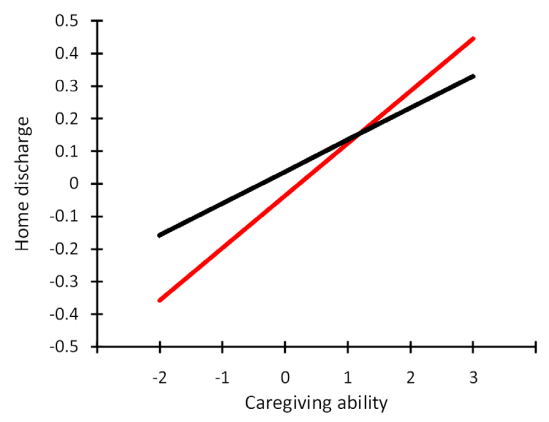

Mean11SD: $y=0.1604 * x-0.0357$

Mean+1SD: $y=0.0973 * x+0.0371$

(f) Climbing stairs

e) Bladder management

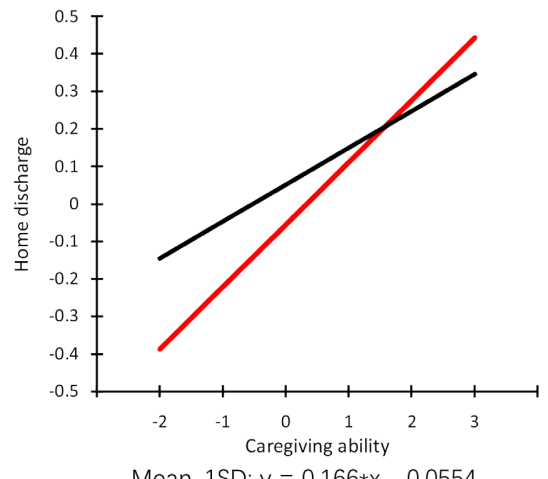

Mean-1SD: $y=0.166 * x-0.0554$ Mean+1SD: $y=0.0982 * x+0.0517$

(b) Bladder management

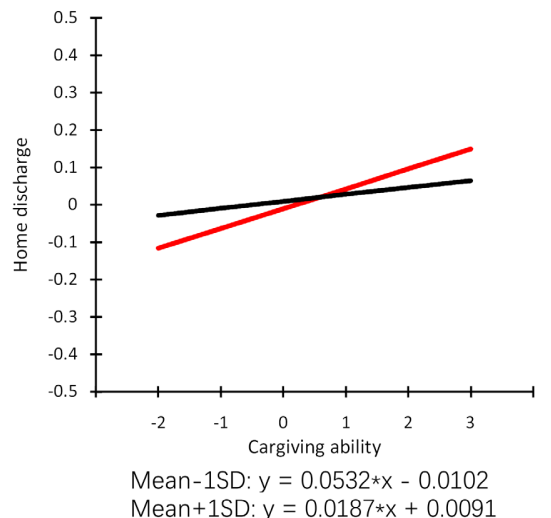

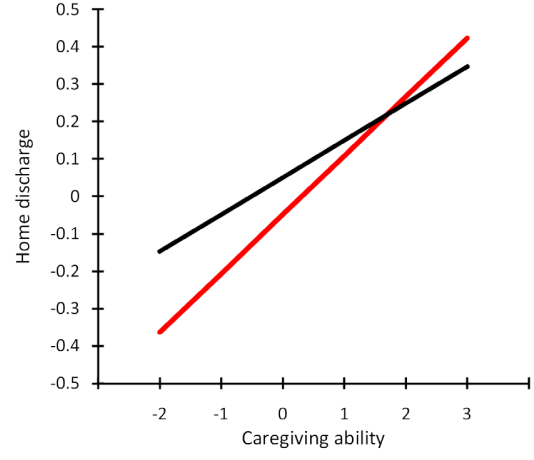

Mean-1SD: $y=0.1575 * x-0.0493$ Mean+1SD: $y=0.0988 * x+0.0503$

(c) Climbing stairs

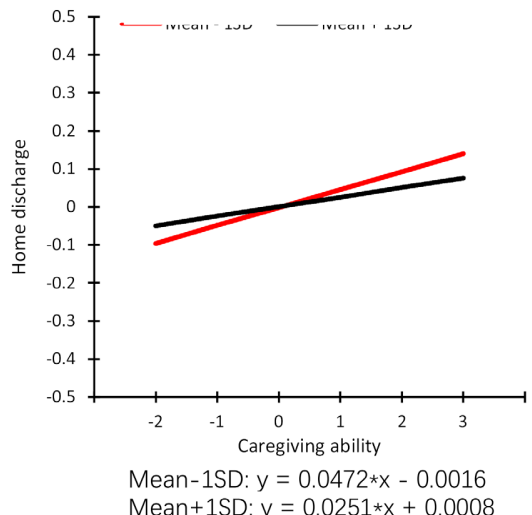

Figure 2. Interaction plots of caregiving ability predicting home discharge outcomes under each self-care as moderator factor. Black line; Mean + 1SD, Red line; Mean - 1SD. SD; standard deviation. 
(A) Moderate group

(a) Eating

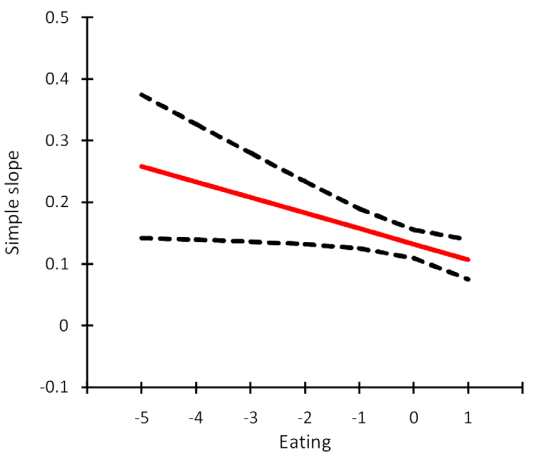

(d) Dressing lower body

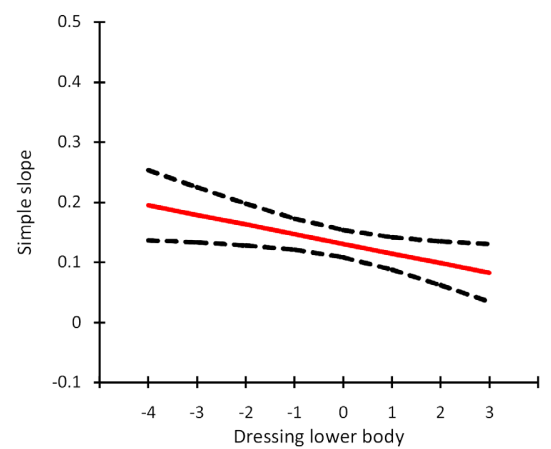

(B) Mild group

(a) Dressing upper body

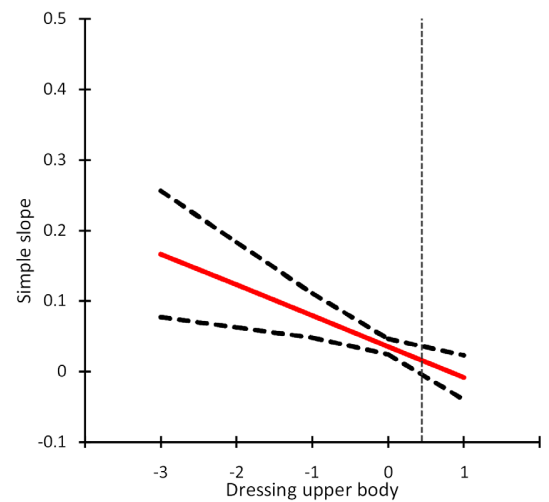

(b) Grooming

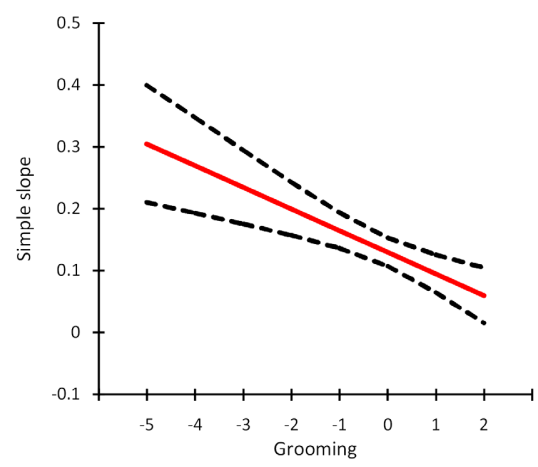

(e) Bladder management

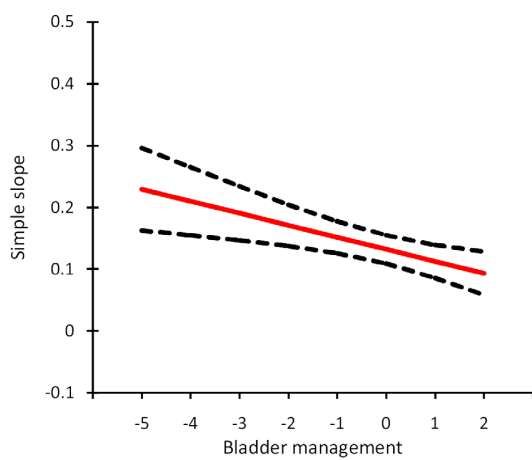

(b) Bladder management

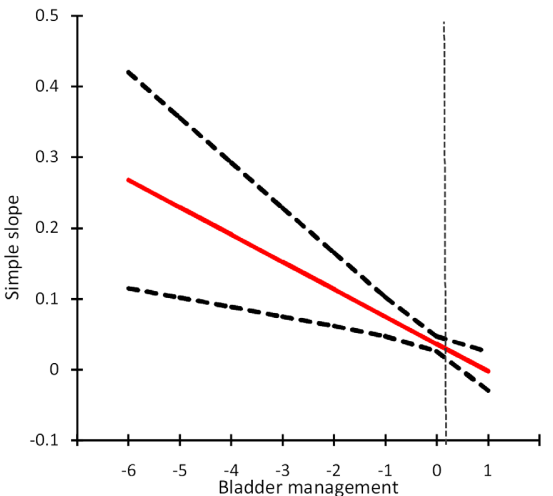

(c) Bathing

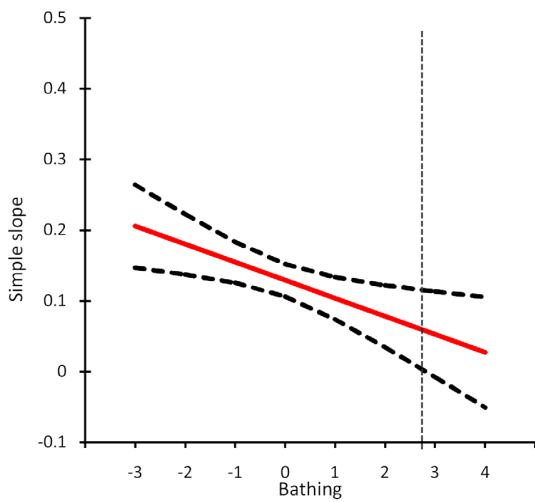

(f) Climbing stairs

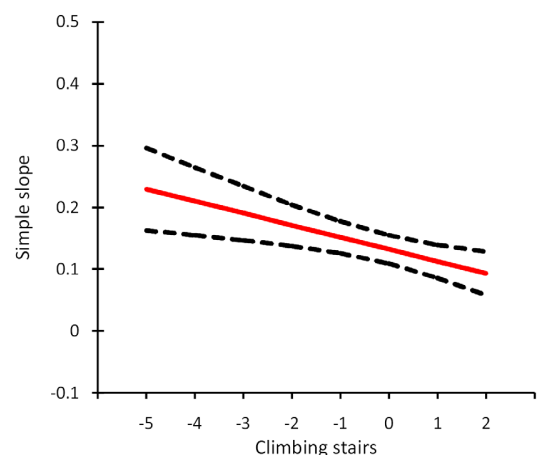

(c) Climbing stairs

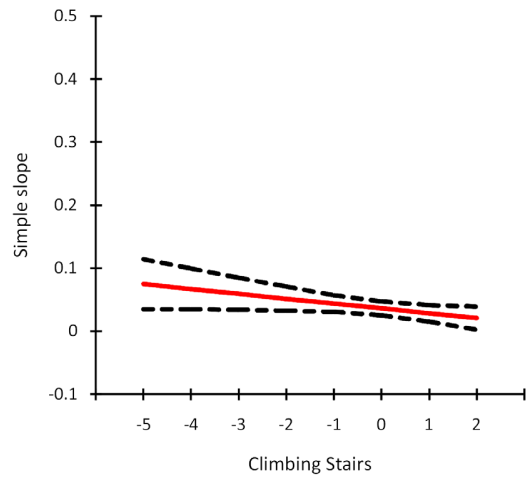

Figure 3. A region of significance and $95 \%$ confidence band of Simple slope after mean-centering. Center line with red; prediction coefficient of simple slope, up and down curve hatched line with black; $95 \%$ confidence interval that can be used to infer statistical significance. Vertical hatched lines with gray; upper or lower confidence band crosses the zero-line and they represent the boundary between areas where the slope is significantly areas where the slope is statistically not significant. Horizontal axis; range is from minimum to maximum of each self-care.

\section{Discussion}

This study investigated the interaction between self-care and caregiving ability in stroke patients based on the m-FIM score at discharge using multi-facility data (JRD). The main finding suggested that self-care in the mild and moderate groups revealed an interaction based on the discharge destination, implying that caregiving ability impacted home discharge differentially across self-care levels. Moreover, the common aspects of self-care that influenced home discharge were blad- 
der management and climbing stairs.

In recent times, the number of in-home post-stroke patients has been increasing; thus, the need for caregiving is also increasing. However, as the age of caregivers and burden are also increasing, stroke patients tend to be obliged to be discharged to nursing homes. Thus, ADL independence level is important to continue living at home. A previous study reported that the average scores of m-FIM and c-FIM for stroke patients who could be discharged to their homes regardless of whether they were living alone or with their family was 66 78 and $26-28$, respectively [21] [22]. Both average scores in this study were similar to those of previous studies, except for those in the severe group. Additionally, the home discharge rate was also close to that of previous studies.

The severe group did not reveal an interaction between self-care and caregiving ability upon home discharge in this study. Compared with the other groups, most tasks in the severe group were at complete dependence level, which is defined as total or maximum assistance in taking care, except for eating. Moreover, the m-FIM score of self-care was not significant by comparison between groups based on discharge destination. This may be because the self-care level does not have a strong relationship with home discharge in severe cases, and discharge depends on caregiving ability.

Upper limb function and sitting balance are important factors in self-care post stroke. The usefulness of the upper limbs is related to improving ADL [23] [24] [25]. Moreover, it is necessary not only to improve the functioning of upper limbs for taking food to the mouth, but also to improve the grip functioning for handling the dishes and cutlery corresponding to the other upper limb's action while eating. Besides this, in dressing, sensitive control of the upper limbs is needed to put the arm through a sleeve or put feet through a piece of clothing. If such actions are not controlled, spills or disheveled clothes might happen, and caregiving will be required for adapting to these problems. Therefore, upper limb function is critical for conducting self-care.

In addition, stability of sitting and standing influence the control of the unaffected/affected or bilateral upper limbs when doing self-care, and patients with stroke are often cared for when they are in a seated position. Trunk function is relevant to balanced control of the center of gravity and for upper limb actions in ADL [26] [27]. Moreover, it impacts advanced applied activities like gait. Hence, it is assumed that performance of affected upper limbs and trunk function in self-care impacts affects not only the quantity but also the quality of other activities.

Self-care, which had an interaction in this study, involves basic activities in daily life and requires frequent repetitions. For instance, grooming consumes approximately $20 \%$ of daily time [28] [29] [30]. Caregivers have to deal with such self-care at home, and it is possible that they are forced to spend time to adapt to varied care challenges. Such time constraints account for one of several elements of the caregiving burden. Hence, it is assumed that the self-care ability of the patients exhibits an interaction with caregiving ability upon home discharge.

However, these interactions were more evident in the moderate group than in 
the mild group. The characteristics of the moderate group were significant among group comparison, and their independence levels were moderate to minimal. Caregivers spent more time caring for this group, which caused their burden to increase [31]. Therefore, it is assumed that self-care interaction depends on the caregiver's ability, in the case of home discharge.

\subsection{Bladder Management}

Daily bladder movement frequency in elderly people tends to be greater, while void volume at one time is less compared to that in younger people. Chronic intestinal constipation is a common bowel symptom in post-stroke patients, while diminished frequency is another reported bowel dysfunction [32] [33] [34]. Further, overactive bladder is a common stroke symptom [27], with a frequency of eight or more times in 24 hours. Such complex sphincter impairment related disabilities have a negative influence on their quality of life (QOL) [35] [36]. The increased burden on caregivers for patients with sphincter impairment at home made them feel entrapped, further impacting their health [37]. Thus, sphincter dysfunction impacts the ADL performance and increases the burden on caregivers [38] [39]. In this study, bladder management level was independent to minimal assist. The frequency of bladder management failure was defined as once per day to never (zero); that is, the frequency of once-daily was $2-6$ times per week. Moreover, modified independence (level 6) was defined as taking more time than normal. Caregivers understand that the failure risk of bladder management is high in such situations, and that they need to pay constant attention to avoid the risk; this accounts for the psychological burden on the caregivers.

Pelvic floor muscles (PFM) have a relation with not only the bladder sphincter but also with the trunk function; thus, trunk function has is relevant to ADL. Interaction of trunk function with other self-care activities leads to improved bladder management, and the burden on caregivers is reduced. Therefore, sphincter independence is an important factor in caregivers' QOL, and it was assumed that bladder management was related to the interaction with the caregiving ability.

\subsection{Climbing Stairs}

The home setting is critical for home discharge in post-stroke patients. Adjustments in home setting comprising layout change, a threshold with no step, and slip-resistant flooring may have to be ensured [38]. When post-stroke patients live at home, in addition to walking, they encounter steps and differences in floor levels, increasing the risk of falling. In this study, the minimum required level of climbing stairs was identified as above level 3 to 4 . This situation strains the caregivers as it takes great effort to ensure that the stroke patient does not fall owing to even a slight step. In addition, the knee joint has been reported to be highly loaded when climbing the stairs, with an average peak resultant force, in percent of body weight, three times higher compared with gait [40], indicating that the caregiving burden is greater while climbing stairs. Moreover, falling and 
fall-related injuries are reported to be serious problems for home-dwelling stroke patients [41]. Thus, it requires greater direct caregiving as well as advanced techniques compared with other self-care activities. Moreover, falling is a negative factor and is assumed to lead to negative feelings, such as perceived rejection by family members about home discharge. Therefore, it is assumed that the independence level of climbing stairs impacted caregiving ability and home discharge.

Climbing stairs is most difficult activity for post-stroke. For this reason, rehabilitation intervention toward discharge is mainly gait training. It is assumed that an interaction climbing stairs in this study does not require performing that activity perfectly, and single-foot standing ability while climbing stairs is important to navigate a small step in the home.

\section{Conclusions}

In this study based on discharged m-FIM score, patients were classified into three groups, and then the interaction of self-care and caregiving ability on the discharge destination was investigated. Self-care interaction was not observed in the severe group, and was mainly observed in the moderate group, according to the analysis of JRD data. In addition, bladder management and climbing stairs had similar interactions in the moderate and mild groups. Moreover, caregiving ability interaction in mild group showed more influence than moderate group.

A limitation to this study was that home-modification planed after discharge (e.g., layout change, barrier-free) was not considered in setting the control variables for the three groups. Hence, future research should investigate an interaction based on hierarchy, using home-modification as a variable, with discharge m-FIM score.

Therefore, this study's findings suggest that there is a need not only for gait training but also for intervention for single-foot standing ability to get over a small step in the home to facilitate home discharge of stroke patients. Moreover, caregiving ability was suggested to be an important factor in the mild group. Future research should be conducted on three-way interaction based on hierarchy, with discharge m-FIM score, using a value as home-modification, and should further test and discuss the influencing factors.

\section{Acknowledgments}

This study used the Japan Rehabilitation Database managed by the Japan Association of Rehabilitation Database, to whom we express our gratitude. The contents and conclusions of this study are not the opinions of the Association but exclusively those of the authors.

\section{Funding}

This research received no specific grant from any funding agency in the public, commercial, or not-for-profit sectors. 


\section{Conflicts of Interest}

The author declares no conflicts of interest regarding the publication of this paper.

\section{References}

[1] Matsuyama, A. (2018) Factors Associated with the Walking Ability of Hemiplegic Stroke Patients. The Open Nursing Journal, 8, 14-25. https://doi.org/10.4236/ojn.2018.81002

[2] Janice, J.E. and Tang, P.-F. (2007) Gait Training Strategies to Optimize Walking Ability in People with Stroke: A Synthesis of the Evidence. Expert Review of Neurotherapeutics, 24, 1417-1436. https://doi.org/10.1586/14737175.7.10.1417

[3] van Wegen, E.E.H., Johannes, C.F.K., Heymans, M.W., et al. (2011) Early Prediction of Outcome of Activities of Daily Living after Stroke: A Systematic Review. Stroke, 42, 1482-1488. https://doi.org/10.1161/STROKEAHA.110.604090

[4] White, C.L., Lauzon, S., Yaffe, M.J. and Wood-Dauphinee, S. (2004) Toward a Model of Quality of Life for Family Caregivers of Stroke Survivors. Quality of Life Research, 13, 625-638. https://doi.org/10.1023/B:QURE.0000021312.37592.4f

[5] Ugur, H.G. and Erci, B. (2019) The Effect of Home Care for Stroke Patients and Education of Caregivers on the Caregiver Burden and Quality of Life. Acta Clinica Croatica, 58, 321-332.

[6] Hesamzadeh, A., Dalvandi, A., Bagher, M.S., Fallahi, K.M., Ahmadi, F. and Mosavi, A.N. (2017) Family Caregivers' Experience of Activities of Daily Living Handling in Older Adult with Stroke: A Qualitative Research in the Iranian Context. Scandinavian Journal of Caring Sciences, 31, 515-526. https://doi.org/10.1111/scs.12365

[7] Xie, H., Cheng, C., Tao, Y., Zhang, J., Robert, D., et al. (2016) Quality of Life in Chinese Family Caregivers for Elderly People with Chronic Diseases. Health and Quality of Life Outcomes, 14, 99. https://doi.org/10.1186/s12955-016-0504-9

[8] Watanabe, A., Fukuda, M., Suzuki, M., Kawaguchi, T., Habata, T., Akutsu, T., et al. (2014) Factors Decreasing Caregiver Burden to Allow Patients with Cerebrovascular Disease to Continue in Long-Term Home Care. Journal of Stroke and Cerebrovascular Diseases, 24, 424-430. https://doi.org/10.1016/j.jstrokecerebrovasdis.2014.09.013

[9] Menon, B., Salini, P., Habeeba, K., Conjeevaram, J. and Munisusmitha, K. (2017) Female Caregivers and Stroke Severity Determines Caregiver Stress in Stroke Patients. Annals of Indian Academy of Neurology, 20, 418-424. https://doi.org/10.4103/aian.AIAN_203_17

[10] Tsai, Y.H., Lou, M.F., Feng, T.H., Chu, T.L., Chen, Y.J. and Liu, H.E. (2018) Mediating Effects of Burden on Quality of Life for Caregivers of First-Time Stroke Patients Discharged from the Hospital within One Year. BMC Neurology, 18, Article No. 50. https://doi.org/10.1186/s12883-018-1057-9

[11] Ostwald, S.K., Bernal, M.P., Cron, S.G. and Godwin, K.M. (2009) Stress Experienced by Stroke Survivors and Spousal Caregivers during the First Year after Discharge from Inpatient Rehabilitation. Topics in Stroke Rehabilitation, 16, 93-104. https://doi.org/10.1310/tsr1602-93

[12] Alexander, W., Michelle, T. and Sepideh, P. (2020) Factors Associated with Community versus Personal Care Home Discharges after Inpatient Stroke Rehabilitation: The Need for a Pre-Admission Predictive Model. Topics in Stroke Rehabilitation, 27, 173-180. https://doi.org/10.1080/10749357.2019.1682369 
[13] Clery, A., Bhalla, A., Bisquera, A., Skolarus, L.E., Marshall, I., et al. (2020) Long-Term Trends in Stroke Survivors Discharged to Care Homes: The South London Stroke Register. Stroke, 51, 179-185. https://doi.org/10.1161/STROKEAHA.119.026618

[14] Everink, I.H., van Haastregt, J.C., van Hoof, S.J., Schols, J.M. and Kempen, G.I. (2016) Factors Influencing Home Discharge after Inpatient Rehabilitation of Older Patients: A Systematic Review. BMC Geriatrics, 16, Article No. 5. https://doi.org/10.1186/s12877-016-0187-4

[15] Kimura, T. (2021) Interaction between Self-Care and Caregiving Ability on Home Discharged Stroke Patients Based on Motor Functional Independence Measure Score in Recovery Ward. Open Journal of Therapy and Rehabilitation, 9, 42-56. https://doi.org/10.4236/ojtr.2021.92004

[16] Chen, H.F., Wu, C.Y., Lin, K.C., Chen, C.L., Huang, P.C., Hsieh, C.J., et al. (2013) Rasch Validation of a Combined Measure of Basic and Extended Daily Life Functioning after Stroke. Neurorehabilitation and Neural Repair, 27, 125-132. https://doi.org/10.1177/1545968312457828

[17] Lopes, P.G., Lopes, J.A., Brito, C.M., Alfieri, F.M. and Battistella, R.L. (2015) Relationships of Balance, Gait Performance, and Functional Outcome in Chronic Stroke Patients: A Comparison of Left and Right Lesions. Biomedical Research, 2015, Article ID: 716042. https://doi.org/10.1155/2015/716042

[18] Jørgensen, H.S., Nakayama, H., Raaschou, H.O. and Olsen, T.S. (1995) Intracerebral Hemorrhage versus Infarction: Stroke Severity, Risk Factors, and Prognosis. Annals of Neurology, 38, 45-50. https://doi.org/10.1002/ana.410380110

[19] Brankovic, M., Kardys, I., Steyerberg, E.W., Lemeshow, S., Markovic, M., Rizopoulos, D., et al. (2019) Understanding of Interaction [Subgroup] Analysis in Clinical Trials. European Journal of Clinical Investigation, 49, e13145. https://doi.org/10.1111/eci.13145

[20] Andersson, U., Cuervo-Cazurra, A. and Nielsen, B.B. (2014) Explaining Interaction Effects within and across Levels of Analysis. Journal of International Business Studies, 45, 1063-1071. https://doi.org/10.1057/jibs.2014.50

[21] Mutai, H., Furukawa, T., Araki, K., Misawa, K. and Hanihara, T. (2012) Factors Associated with Functional Recovery and Home Discharge in Stroke Patients Admitted to a Convalescent Rehabilitation Ward. Geriatrics \& Gerontology International, 12, 215-222. https://doi.org/10.1111/j.1447-0594.2011.00747.x

[22] Miura, H., Shimizu, S., Noma, T., Ichinosawa, Y., Shimose, R., Tsunoda, S., et al. (2018) Post-Stroke Patients' Activities of Daily Living Levels for Discharge to Return Home to Live Alone. The Kitasato Medical Journal, 48, 118-127.

[23] Uno, Y., Kawato, M. and Suzuki, R. (1989) Formation and Control of Optimal Trajectory in Human Multijoint Arm Movement. Biological Cybernetics, 61, 89-101.

https://doi.org/10.1007/BF00204593

[24] Yamamoto, H., Takeda, K., Koyama, S., Morishima, K., Hirakawa, Y., Motoya, I., et al. (2020) Relationship between Upper Limb Motor Function and Activities of Daily Living after Removing the Influence of Lower Limb Motor Function in Subacute Patients with Stroke: A Crosssectional Study. Hong Kong Journal of Occupational Therapy, 33, 12-17. https://doi.org/10.1177/1569186120926609

[25] Kim, D. (2016) The Effects of Hand Strength on Upper Extremity Function and Activities of Daily Living in Stroke Patients, with a Focus on Right Hemiplegia. The Journal of Physical Therapy Science, 28, 2565-2567. https://doi.org/10.1589/jpts.28.2565

[26] Wee, S.K., Hughes, A.M., Warner, M.B., Brown, S., Cranny, A., Mazomenos, E.B., et 
al. (2015) Effect of Trunk Support on Upper Extremity Function in People with Chronic Stroke and People Who Are Healthy. Physical Therapy, 95, 1163-1171. https://doi.org/10.2522/ptj.20140487

[27] Song, B.K. (2011) The Effect of Upper Extremity Training with a Focus on Functional Reaching, on Trunk Control and ADL Performance in Post-Stroke Hemiplegic Patients. Journal of the Korean Society of Physical Medicine, 23, 71-77. http://www.kptjournal.org/journal/download_pdf.php?spage=71\&volume=23\&nu mber $=3$

[28] Roberts, S.G.B. and Dunbar, R.I.M. (2011) Communication in Social Networks: Effects of Kinship, Network Size, and Emotional Closeness. Personal Relationships, 18, 439-452. https://doi.org/10.1111/j.1475-6811.2010.01310.x

[29] Masanori, T. (2018) Two Types of Social Grooming Methods Depending on the Trade-Off between the Number and Strength of Social Relationships. Royal Society Open Science, 5, Article ID: 5180148. https://doi.org/10.1098/rsos.180148

[30] Kwok, C., McIntyre, A., Janzen, S., Mays, R. and Teasell, R. (2015) Oral Care Post Stroke: A Scoping Review. Journal of Oral Science, 42, 65-74.

https://doi.org/10.1111/joor.12229

[31] Dewey, H.M., Thrift, A.G., Mihalopoulos, C., Carter, R., Macdonell, R.A., McNil, J.J., et al. (2002) Informal Care for Stroke Survivors: Results from the North East Melbourne Stroke Incidence Study [NEMESIS]. Stroke, 33, 1028-1033. https://doi.org/10.1161/01.STR.0000013067.24300.B0

[32] Itoh, Y., Yamada, S., Konoeda, F., Koizumi, K., Nagata, H. and Oya, M. (2013) Burden of Overactive Bladder Symptom on Quality of Life in Stroke Patients. Neurourology and Urodynamics, 32, 428-434. https://doi.org/10.1002/nau.22336

[33] Abrams, P., Cardozo, L., Fall, M., Griffiths, D., Rosier, P., Ulmsten, U., et al. (2002) The Standardization of Terminology of Lower Urinary Tract Function: Report from the Standardization Sub-Committee of the International Continence Society. Neurourology and Urodynamics, 21, 167-178. https://doi.org/10.1002/nau.10052

[34] Coyne, K.S., Sexton, C.C., Irwin, D.E., Kopp, Z.S., Kelleher, C.J. and Milsom, I.T. (2008) The Impact of Overactive Bladder, Incontinence and Other Lower Urinary Tract Symptoms on Quality of Life, Work Productivity, Sexuality and Emotional Well-Being in Men and Women: Results from the EPIC Study. BJU International, 101, 1388-1395. https://doi.org/10.1111/j.1464-410X.2008.07601.x

[35] Wein, A.J. and Rovner, E.S. (2002) Definition and Epidemiology of Overactive Bladder. Urology, 60, 7-12. https://doi.org/10.1016/S0090-4295(02)01784-3

[36] Corrado, B., Giardulli, B., Polito, F., Aprea, S., Lanzano, M. and Dodaro, C. (2020) The Impact of Urinary Incontinence on Quality of Life: A Cross-Sectional Study in the Metropolitan City of Naples. Geriatrics, 5, 96.

https://doi.org/10.3390/geriatrics5040096

[37] Ayşegül, Ç. and Belgüzar, K. (2019) The Relationship between the Stroke Survivors' Functional Status and Their Informal Caregivers' Burden and Quality of Life. AIMS Medical Science, 6, 115-127. https://doi.org/10.3934/medsci.2019.1.115

[38] Marcheschi, E., Von Koch, L., Pessah-Rasmussen, H. and Elf, M. (2018) Home Setting after Stroke, Facilitators and Barriers: A Systematic Literature Review. Health \& Social Care in the Community, 26, e451-e459. https://doi.org/10.1111/hsc.12518

[39] Oliva-Moreno, J., Aranda-Reneo, I., Vilaplana-Prieto, C., González-Domínguez, A. and Hidalgo-Vega, A. (2012) Economic Valuation of Informal Care in Cerebrovascular Accident Survivors in Spain. BMC Health Services Research, 13, Article No. 508. https://doi.org/10.1186/1472-6963-13-508 
[40] Kutzner, I., Heinlein, B., Graichen, F., Bender, A., Rohlmann, A., Halder, A., et al. (2010) Loading of the Knee Joint during Activities of Daily Living Measured in Vivo in Five Subjects. Journal of Biomechanics, 43, 2164-2173.

https://doi.org/10.1016/j.jbiomech.2010.03.046

[41] Forster, A. and Young, J. (1995) Incidence and Consequences of Falls Due to Stroke: A Systematic Inquiry. BMJ, 311, 83-86. https://doi.org/10.1136/bmj.311.6997.83 